\title{
Arthritis in HIV
}

Sir,

I read with great interest the clinical brief "Arthritis in HIV" by Ahuja et al and I have two points to raise: (1) The child in the given case had a clinical history consistent with rheumatic arthritis (swelling of large joints off and on, though it was not mentioned whether it was migratory in nature, which was tender, markedly erythematous, restricting the movements and reasonably good response to anti-inflammatory agents). ${ }^{2}$ ESR was also suggested. Even then, no comment has been made about the status of heart, nor any investigation was done to look for rheumatic activity (ASO titres, ECG etc.) (2) Since the child has been diagnosed as a case of HIV, suggestive by past history of herpes zoster, mild oral candidiasis, positive ELISA and western blot, a CD4 TCell count was compulsory to decide the therapy, prognosticate and monitor the progress of treatment. ${ }^{3,4}$ Instead of doing VDRL, rheumatoid factor, anti-nuclear antibody and double-stranded DNA, which seems futile tests in this case (Nothing to suggest Syphilis, rheumatoid arthritis and SLE), a CD4 cell count would have been much useful and necessary investigation, specially looking at the gravity of the disease.

\author{
Pankaj Garg, \\ D-584, Kamla Nagar, Agra, \\ Uttar Pradesh-282 005 \\ E-mail: pankajparul8@hotmail.com
}

\section{REFERENCES}

1. Ahuja AR, Oak J, Sawant S, Kulkarni MV. Arthritis in HIV. Indian I Pediatr 2003; $70: 835-836$

2. Todd JK. Rheumatic Fever. In Behrman RE, Kliegmann RM, Jenson HB, eds. Nelsons Textbook of Pediatrics. $16^{\text {th }}$ edn. Philadelphia WB Saunders Company; 2000; 806-810.

3. Mills GD, Jones PL. Relationship between CD4 Lymphocyte counts and AIDS mortality (1986-1991). AIDS 1993; 7: 13831386

4. Colford JM, Ngo L, Tager I. Factors associated with survival in human immunodeficiency virus with very low CD4 counts. Am J Epidemiol 1994; 139 : 206-218.

\section{(Author's Reply)}

\section{Reply to Comment 1}

The Child reported in our case had history of arthritis since the past one year. Although, large joints were affected as pointed out, the chronic history made a diagnosis of rheumatic fever unlikely. Also, there was no tachycardia and cardiac examination was clinically normal. Therefore, investigations for rheumatic fever and detailed cardiac evaluation were not considered necessary. There was some response to treatment with anti-inflammatory agents in our patient, but it took two weeks and was incomplete unlike what is expected with rheumatic arthritis.

\section{Reply to Comment 2}

We agree that in view of a diagnosis of HIV infection, $\mathrm{CD} 4 \mathrm{~T}$ cell count should have been done to determine the severity of immunocompromise and plan further management. However, CD4 T cell count estimation is not done at our hospital. The parents were unable to do expensive investigations from elsewhere. Also, the child was lost to further follow up. Investigations like ANA, double stranded DNA, RA factor were done initially on presentation, before a diagnosis of HIV infection was made, to rule out other causes of chronic arthropathy.

Sanjeev R. Ahuja, 14/B, Usha Sadan,

Ind Floor, Near Colaba Post Office, Mumbai-400005.

Fax : 91-22-4076100

E-mail : drsanjeevahuja73@hotmail.com 